\section{Research of nitroxynil residues in bovine milk following a single administration in the dry period by ultra-performance liquid chromatography tandem mass spectrometry}

\author{
Claudia Chirollo, ${ }^{1}$ Tiziana Pepe, ${ }^{1}$ \\ Marina Ceruso, ${ }^{1}$ Rosanna Taglialatela, ${ }^{1}$ \\ Giorgio Smaldone, ${ }^{1}$ Martin Danaher ${ }^{2}$ \\ Riona Sayers, ${ }^{3}$ Yris Bloemhoff ${ }^{3}$ \\ 'Dipartimento di Medicina Veterinaria e \\ Produzioni Animali, Università Federico \\ II, Napoli, Italy; ${ }^{2}$ Teagasc Food Research \\ Dublin; ${ }^{3}$ Moorepark - Animal \& Grassland \\ Research and Innovation Centre, Teagasc, \\ Cork, Ireland
}

\section{Abstract}

Nitroxynil (NIT) is a halogenated phenol used to control fascioliasis in cattle and sheep. The Commission Regulation EU No 37/2010 has established maximum residue limits for NIT in bovine and ovine muscle ( $\left.400 \mu \mathrm{g} \mathrm{kg}^{-1}\right)$, fat $\left(200 \mu \mathrm{kg}^{-1}\right)$, liver $\left(20 \mu \mathrm{gg}^{-1}\right)$ and kidney $\left(400 \mu \mathrm{gg}^{-1}\right)$, and more recently in bovine and ovine milk $\left(20 \mu \mathrm{g} \mathrm{kg}^{-1}\right)$. Thirty-five pregnant dairy cows were treated in this study with nitroxynil (340 mg/mL solution for injection) at the recommended dose of $10 \mathrm{mg} / \mathrm{kg}$ body weight at the start of the dry period, i.e. 53 to 74 days before the expected calving. Calving occurred between 43 days and 79 days after treatment. The concentrations of NIT in the milk were monitored for up to 120 days after calving. NIT residues were extracted using acetonitrile; magnesium sulfate and sodium chloride were added to induce liquid-liquid partitioning and purified by dispersive solid phase extraction for clean-up. NIT was detected by ultra high performance liquid chromatography coupled to tandem mass spectrometry (UHPLC-MS/MS) in negative ionization mode. The highest concentrations of this drug were found in two animals at the first milking, 48 and 53 day post treatment with levels of 362 and $657 \mu \mathrm{g} \mathrm{kg}^{-1}$, respectively. NIT residues were below the limit of detection of the method $\left(0.24 \mu \mathrm{g} / \mathrm{kg}^{-1}\right)$ between 67 and 106 day post-treatment. Following calving, residues rapidly depleted in animals and were non-detectable from 10 to 38 days post-calving. In particular, in all animals milk resulted compliant $(<20$ $\mu \mathrm{g} / \mathrm{kg}^{-1}$ ) three days post partum.

\section{Introduction}

Nitroxynil (NIT) (3-iodo-4-hydroxy-5-nitrobenzonitrile) is a phenol derivative (Devis et al., 1966) used in cattle and sheep for the control of fascioliasis (McKellar and Kinabo, 1991). When compared with other fasciolicides, this compound shows high activity against both adult and immature liver flukes (Martínez-Valladares et al., 2010; McKinstry et al., 2009; Hutchinson et al., 2009). Recently the Commission Regulation (EU) No 201/2012 (European Commission, 2012) has amended the Annex of the Regulation (EU) No 37/2010 (European Commission, 2010) on pharmacologically active substances and their classification regarding maximum residue limits in foodstuffs of animal origin and maximum residue limits (MRLs) for the marker residue NIT in bovine and ovine milk was established at 20 $\mathrm{g} / \mathrm{kg}^{-1}$. MRLs set for muscle, fat, liver and kidney have not been modified and amounted to $400,200,20$ and $400 \mu \mathrm{g} \mathrm{kg}^{-1}$, respectively.

NIT residues, compared to other classes of anthelmintics, have the longest half-life in the body (McKellar and Kinabo, 1991). This is due to its strong plasma protein binding which is more than $98 \%$ for this compound (Alvinerie $e t$ al., 1995). The selective mode of action of this highly protein-bound anthelmintic may be explained, in part, by its effect against bloodsucking parasites, concentrating the anthelmintic in the parasite (without the high tissues levels being produced in the host). The high level of protein binding may explain the selective effect of these agents, and the fact that well bled out carcasses have low tissues residue levels. Thus, the mode of action of this group of anthelmintic involves the selective delivery of the proton ionophores to the parasite because of the high level of plasma-protein binding. This study was conducted in pregnant dairy cows $(n=35)$ at the beginning of the dry period because they are the target animal population for the investigated treatment. The occurrence and the depletion of NIT in bovine milk after calving was investigated.

\section{Materials and Methods}

No. 35 healthy pregnant Friesian-Holstein dairy cows from Animal \& Grassland Research and Innovation Centre, Fermoy, Ireland were selected for the experiment. The cows used in this study, with an average body weight of 600 $\mathrm{kg}$, had not been treated with products containing NIT within 12 months before the start of this study, as documented by the farm records. The cows were treated at the start of the dry period, from 53 to 74 days before the expected calving with TRODAX $340 \mathrm{mg} / \mathrm{mL}$ (Merial
Correspondence: Claudia Chirollo, Dipartimento di Medicina Veterinaria e Produzioni Animali, Università di Napoli Federico II, via F. Delpino 1, 80137 Napoli, Italy.

Tel. +39.081.2536082 - Fax: +39.081.454683.

E-mail: claudia.chirollo@unina.it

Key words: Nitroxynil, Milk, Dry cows, UHPLCMS/MS.

Conflict of interests: the authors declare no potential conflict of interests.

Received for publication: 11 May 2013.

Accepted for publication: 23 July 2013.

This work is licensed under a Creative Commons Attribution 3.0 License (by-nc 3.0).

(C) Copyright C. Chirollo et al., 2013 Licensee PAGEPress, Italy

Italian Journal of Food Safety 2013; 2:e43 doi:10.4081/ijfs.2013.e43

Animal Health, Harlow, UK). This corresponds to $1.5 \mathrm{~mL}$ solution for injection per $50 \mathrm{~kg}$ body weight. The administered dose was calculated on the basis of the estimated average body weight of the cows. After calving, milk samples were taken daily for the first 4 days and then every 3 days for up to the $120^{\text {th }}$ day and stored at $-20^{\circ} \mathrm{C}$ until analysis. Ultra-pure water $(18.2$ MOhm) was generated in-house using a Millipore (Cork, Ireland) water purification system. HPLC-grade methanol $(\mathrm{MeOH})$ and acetonitrile (MeCN), 99.5\% deuterated methanol (MeOH-d), and ammonium formate (puriss pro analysi) were sourced from SigmaAldrich (Dublin, Ireland). Dimethyl sulfoxide (DMSO), isopropyl-alcohol (IPA), and glacial acetic acid (HOAc) were obtained from BDH Chemicals Ltd. (Poole, UK). Pre-weighed mixtures of $4 \mathrm{~g}$ anhydrous magnesium sulphate $\left(\mathrm{MgSO}_{4}\right)$ and $1 \mathrm{~g}$ sodium chloride $(\mathrm{NaCl})$ in 50 $\mathrm{mL}$ centrifuge tubes, and $1.5 \mathrm{~g} \mathrm{MgSO}_{4}$ and 0.5 $\mathrm{g} \mathrm{C}_{18}$ in $50 \mathrm{~mL}$ centrifuge tubes were obtained from UCT Inc. (Bristol, PA, USA). Organic milk, for control samples, was purchased in supermarkets and tested for residues prior to analysis.

Nitroxynil and 13C Nitroxynil were purchased from Sigma-Aldrich and Witega (Berlin, Germany) laboratories, respectively. Primary stock standard solution was prepared in $\mathrm{MeOH}$ at concentrations of 4000 and 1000 $\mu \mathrm{g} \mathrm{mL}^{-1}$ for nitroxynil and $13 \mathrm{C}$ nitroxynil, respectively.

Intermediate working standard solution was

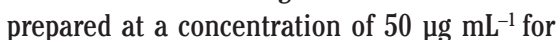
nitroxynil in $\mathrm{MeOH}$. A working internal stan-

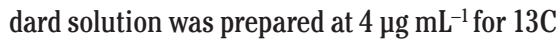
nitroxynil in MeOH-d.

Extracted matrix calibrants were prepared by fortifying negative milk samples prior to 
extraction with a working standard mix, prepared at the following concentrations: $0.1,0.25$, $0.5,1,2.5$, and $5 \mu \mathrm{g} \mathrm{mL} \mathrm{m}^{-1}$, standard 1 to 6 , respectively. Matrix-matched calibration curves were prepared by fortifying matrix blanks before extraction with $100 \mu \mathrm{L}$ of the standards to give working standard curves in the sample equivalent range of 1 to $50 \mu \mathrm{gg}^{-1}$. Samples with values above the concentration of $50 \mu \mathrm{g}$ $\mathrm{kg}^{-1}$ were diluted with control milk. An additional four blank matrix samples (recovery controls) were fortified after extraction, two with Std $2(50 \mu \mathrm{L})$ and two with Std $5(50 \mu \mathrm{L})$ to monitor for loss of analytes during extraction.

A glass dispenser (Dispensette ${ }^{\circledR}$ lll; Brand, Wertheim, Germany) was used for aliquoting MeCN extraction solvent, a Mistral 3000i centrifuge, micro centrifuge (Eppendorf, Hamburg, Germany), a multi-vortexer, a Caliper Life Sciences (Runcorn, UK) Turbovap LV evaporator, and a Transsonic 780LH ultrasonic bath were used for the extraction.

Chromatographic separations were performed using a Waters Acquity UHPLC system (Waters; Milford, MA, USA) comprising of a stainless steel HSS T3 analytical column $(100 \times 2.1 \mathrm{~mm}$, particle size $=1.8 \mathrm{~mm})$ equipped with an in-line filter unit containing a $0.2 \mu \mathrm{m}$ stainless steel replacement filter maintained at a temperature of $60^{\circ} \mathrm{C}$ and the pump was

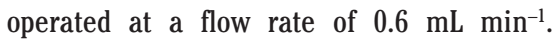
Analytes were separated using a binary gradient elution containing a mobile phase A water:MeCN $(90: 10, \mathrm{v} / \mathrm{v})$ with $0.01 \%$ HOAc and mobile phase B MeOH:MeCN (75:25, v/v) with $5 \mathrm{mM}$ ammonium formate. The gradient profile was as follows: i) $0-0.5 \mathrm{~min}, 100 \% \mathrm{~A}$; ii) $5 \mathrm{~min}$, $50 \%$ A; iii) 7 min, $10 \%$ A; iv) $8.5 \mathrm{~min}, 10 \% \mathrm{~A}$; v) $8.51 \mathrm{~min}, 0 \% \mathrm{~A}$; vi) $9.5 \mathrm{~min}, 0 \% \mathrm{~A}$; vii) 9.51 min, $100 \% \mathrm{~A}$; viii) 13 min $100 \% \mathrm{~A}$. Injection volume was $5 \mu \mathrm{L}$.

NIT residues were quantified using a Waters Quattro Premier XE triple-quadrupole mass spectrometer equipped with an electro- spray ionisation (ESI) interface operating in negative mode (Waters). The UPLC-MS/MS system was controlled by MassLyn ${ }^{\mathrm{TM}}$ software and data was processed using TargetLyn ${ }^{\mathrm{TM}}$ Software (Waters).

Milk samples $(10 \pm 0.1 \mathrm{~g})$ were weighed into centrifuge tubes $(50 \mathrm{~mL})$ and fortified with internal standard and left to sit for $15 \mathrm{~min}$. Acetonitrile $(12 \mathrm{~mL})$ was added to tube one containing $\mathrm{MgSO}_{4}(4 \mathrm{~g})$ and $\mathrm{NaCl}(1 \mathrm{~g})$. The contents of tube one was added to the sample and shaken immediately to extract the residues into the $\mathrm{MeCN}$ layer. The sample was centrifuged for $12 \mathrm{~min}$ at $3500 \mathrm{RPM}(959 \mathrm{~g})$. A dispersive-SPE cleanup step was performed by pouring the supernatant from tube one into tube two $(50 \mathrm{~mL})$ containing $\mathrm{MgSO}_{4}(1.5 \mathrm{~g})$ and $\mathrm{C}_{18}(0.5 \mathrm{~g})$. The samples were vortexed for $30 \mathrm{~s}$ and centrifuged for $10 \mathrm{~min}$ at $2500 \mathrm{RPM}$ (489 g). The supernatant (6 mL) and DMSO $(0.25 \mathrm{~mL})$ were added to a starstedt tube (15 $\mathrm{mL}$ ) and vortexed for one min. The MeCN layer was evaporated under nitrogen at $50^{\circ} \mathrm{C}$ to 0.25 $\mathrm{mL}$. Extracts were filtered through $0.2 \mu \mathrm{m}$ polytetrafluoroethylene (PTFE) syringe filters (Whatman Rezist ${ }^{\circledR}$; Whatman, Maidstone, UK) and injected onto the UPLC-MS/MS system. Any samples that fell outside the calibration range were diluted in negative milk and reanalysed.

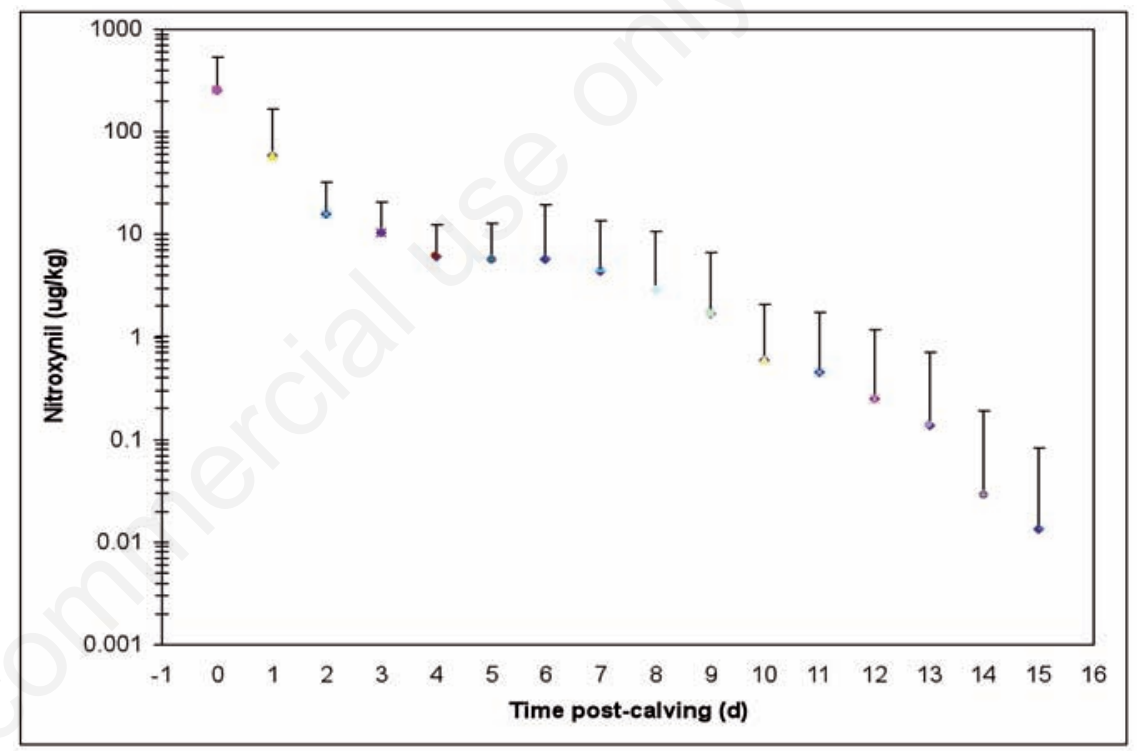

Figure 1. Concentration of Nitroxynil (average of 35 cows) in post-calving period (days) and standard deviation (whiskers).

Table 1. Multiple reaction monitoring window.

\begin{tabular}{|c|c|c|c|c|c|c|c|}
\hline Analyte & $\begin{array}{c}\mathrm{tR} \\
(\mathrm{min})\end{array}$ & $\begin{array}{l}\text { Transition } \\
(\mathrm{m} / \mathrm{z})\end{array}$ & $\begin{array}{c}\text { Cone } \\
\text { (V) }\end{array}$ & $\begin{array}{l}\mathrm{CE} \\
(\mathrm{V})\end{array}$ & $\begin{array}{l}\text { MRM } \\
\text { window }\end{array}$ & ESI Polarity & IS \\
\hline Nitroxynil & 03.46 & $288 \rightarrow 126$ & 36 & 24 & 3 & - & $13 \mathrm{C}$ \\
\hline & & $288 \rightarrow 161$ & 36 & 20 & 3 & - & \\
\hline
\end{tabular}

13C 6 Nitroxynil $\quad 03.46 \quad 295 \rightarrow 126 \quad 40 \quad 25 \quad 3 \quad$ IS

$\mathrm{t}_{\mathrm{R}}$, retention time; CE, collision energy; MRM, multiple reaction monitoring; ESI, electrospray ionisation; IS, internal standard. 
$13 \mathrm{C} 6$ nitroxynil that had been detected in negative ion mode.

In the method developed by Whelan et al.,

The method used for the detection of NIT has been developed previously (Whelan $e t$ al., 2010) for 38 anthelmintic residues in milk. In this study the samples were only monitored for NIT. The multiple reaction monitoring (MRM) window (Table 1) only contains two transitions, one for nitroxynil and one for $13 \mathrm{C} 6$ nitroxynil.

The following transitions were input into MRM windows: $288 a ̀ 126(\mathrm{~m} / z)$ and $288 a ̀ 161$ for nitroxynil; 295à126.69 for the 13C6 nitroxynil internal standard. The retention time, 3.46 min, was the same for both nitroxynil and the incurred samples were mostly highly positive and the sensitivity for negative ionization mode was not so acceptable. NIT was linear in the range $1-50 \mu \mathrm{kg}^{-1}$. Maximum concentration of the drug was $657 \mu^{\mathrm{g} \mathrm{kg}^{-1}}$, which is outside the linear range of the calibration curve. Samples were typically 10 time more concentrated then the range of the curve so, after the first quantification, samples were re-extracted with a dilution in organic milk (analysed previously) by a factor of 1 in 10 or 1 in 5 depending on the initial concentration found in the first extraction.
The results of this study show that NIT residues are very persistent but at low levels in bovine milk of cows treated during the drying period. In two out of 35 animals, residues were found to be detectable up to 102 days after treatment with concentration of $2 \mu \mathrm{g} \mathrm{kg}^{-1}$. The cc for this compound is $0.24 \mu \mathrm{g} \mathrm{kg}^{-1}$.

At the first milking day, in 14 out of 35 animals, NIT residues were above the MRL of 20 $\mu \mathrm{g} \mathrm{kg}^{-1}$ set by European Regulation and the highest levels of the drug were detected in two animals (Table 2) at the $48^{\text {th }}$ and $53^{\text {rd }}$ day post treatment with concentrations of 362 and 657 $\mu \mathrm{g} \mathrm{kg}^{-1}$, respectively.

Mean concentrations of NIT were $<20 \mu \mathrm{g}$ $\mathrm{kg}^{-1}$ three days post-calving (Figure 1).

\begin{tabular}{|c|c|c|c|c|c|c|}
\hline Cow (n) & $\begin{array}{c}\text { Day calved (PT) } \\
\text { ( } 1 \mathrm{~g} / \mathrm{kg})\end{array}$ & $\begin{array}{l}\text { Cmax } \\
\text { (day) }\end{array}$ & $\begin{array}{l}\text { Cmax } \\
\text { (day) }\end{array}$ & $\begin{array}{l}\text { Tmax } \\
\text { (PT day) }\end{array}$ & $\begin{array}{c}\text { LOD } \\
\text { (PC day) }\end{array}$ & LOD \\
\hline 1 & 56 & 06.05 & 57 & 67 & 71 & 15 \\
\hline 2 & 50 & 15.03 & 53 & 74 & 78 & 28 \\
\hline 3 & 73 & 06.05 & 81 & 99 & 102 & 29 \\
\hline 4 & 73 & 20.04 & 74 & 88 & 92 & 19 \\
\hline 5 & 47 & 362.04 & 48 & 78 & 81 & 34 \\
\hline 6 & 62 & 04.04 & 64 & 74 & 78 & 16 \\
\hline 7 & 77 & 06.04 & 78 & 102 & 106 & 29 \\
\hline 8 & 58 & 16.02 & 60 & 67 & 71 & 13 \\
\hline 9 & 71 & 6 & 74 & 88 & 92 & 21 \\
\hline 10 & 57 & 86.09 & 57 & 88 & 92 & 25 \\
\hline 11 & 62 & 07.08 & 64 & 81 & 85 & 23 \\
\hline 12 & 68 & 04.05 & 74 & 88 & 92 & 24 \\
\hline 13 & 53 & 657 & 53 & 81 & 85 & 32 \\
\hline 14 & 80 & 14 & 81 & 102 & 106 & 26 \\
\hline 15 & 76 & 03.01 & 81 & 88 & 92 & 16 \\
\hline 16 & 60 & 02.05 & 67 & 78 & 81 & 21 \\
\hline 17 & 46 & 122.04 & 47 & 78 & 81 & 35 \\
\hline 18 & 47 & 35 & 47 & 64 & 67 & 20 \\
\hline 19 & 73 & 06.09 & 81 & 88 & 92 & 19 \\
\hline 20 & 55 & 19.07 & 57 & 81 & 85 & 30 \\
\hline 21 & 50 & 22.06 & 53 & 81 & 85 & 35 \\
\hline 22 & 50 & 39.07 & 53 & 85 & 88 & 38 \\
\hline 23 & 43 & 81.07 & 49 & 78 & 81 & 38 \\
\hline 24 & 52 & 13.03 & 57 & 81 & 85 & 33 \\
\hline 25 & 56 & 26.03 & 57 & 81 & 85 & 29 \\
\hline 26 & 64 & 07.01 & 67 & 71 & 74 & 10 \\
\hline 27 & 71 & 05.06 & 74 & 81 & 85 & 14 \\
\hline 28 & 64 & 24.01 & 67 & 81 & 85 & 21 \\
\hline 29 & 53 & 07.01 & 57 & 74 & 78 & 25 \\
\hline 30 & 70 & 01.06 & 74 & 78 & 81 & 11 \\
\hline 31 & 62 & 28.04 & 67 & 94 & 99 & 37 \\
\hline 32 & 70 & 08.06 & 71 & 88 & 92 & 22 \\
\hline 33 & 58 & 27.04 & 60 & 92 & 94 & 36 \\
\hline 34 & 51 & 11.06 & 53 & 74 & 78 & 27 \\
\hline 35 & 48 & 237.04 & 48 & 71 & 74 & 26 \\
\hline
\end{tabular}

PT, post-treatment; Cmax, concentration maximum; Tmax, time maximum; LOD, limit of detection; PC, post calving. 


\section{Discussion}

NIT residues were found to be very persistent in milk compared to other anthelmintic drug residues (EMEA, 1998; Whelan et al., 2011). When dairy cows are treated with Trodax (340 mg/mL) at the highest recommended dose of $10 \mathrm{mg}$ nitroxynil per $\mathrm{kg}$ body weight at the beginning of a dry period (about 53 to 80 days before calving - expected calving dates), residues of this flukicide were quantifiable in the milk of the 35 cows until at least 13 days after calving (decision limit, $c c=0.24$ $\mu \mathrm{g} \mathrm{kg}{ }^{-1}$ ).

Highest concentrations of the drug were detected at the first milkings and ranged from 656 to $362 \mu \mathrm{g} \mathrm{kg}^{-1}$ at $53^{\text {rd }}$ and $67^{\text {th }}$ day after treatment, respectively, and were below the limit of detection of the method between $67^{\text {th }}$ and $106^{\text {th }}$ day post treatment.

However, there was considerable variation in levels among animals. This could be due to size difference in body compartments and the amount of fat of each animal. The age and health of the animal also can have an effect on the results, the drugs behave differently in animals with/without parasitic infections (Moreno et al., 2010).

\section{Conclusions}

According to the Commission Regulation 2010/37/EC, NIT residues in bovine milk cannot exceed the MRL of $20 \mathrm{ppb}$. In this study, levels above the MRLs were found only three day after calving.

In conclusion, highest concentrations of NIT occur in the milk produced shortly after calving. This colostrum milk is not suitable for human consumption and is collected separately from the milk that enters the bulk tank on the dairy farm. After the colostrum period, i.e. about 3 days after calving, the concentrations in milk decrease to $10 \mu \mathrm{gg}^{-1}$ or below and residues are non-detectable 10 to 38 days postcalving.

\section{References}

Alvinerie M, Floch R, Galteier P, 1995. Plasma protein binding of nitroxynil in several species. J Vet Pharmacol Ther 14:170-3.

Devis M, Lucas JMS, Rosenbaum J, Wright DE, 1966. 4-Cyano-2-iodo-6-nitrophenol: a new fasciolicide. Nature 211:882-3.

European Commission, 2010. Commission Regulation of 22 December 2009 on pharmacologically active substances and their classification regarding maximum residue limits in foodstuffs of animal origin, 2010/37/EC. In: Official Journal, L15, 20/01/2010.

European Commission, 2012. Commission implementing regulation of 8 March 2012 amending the Annex to Regulation (EU) No $37 / 2010$ on pharmacologically active substances and their classification regarding maximum residue limits in foodstuffs of animal origin, as regards the substance nitroxinil, 201/2012/EC. In: Official Journal, L 71/37, 09/03/2012.

EMEA, 1998. Committee for veterinary medical products. Nitroxynil, summary report, EMEA/MRL/452/98-FINAL. Available from: http://www.ema.europa.eu/docs/en_GB/doc ument_library/Maximum_Residue_Limits _-_Report/2009/11/WC500015185.pdf

Hutchinson GW, Dawson K, Fitzgibbon CC, Martin PJ, 2009. Efficacy of an injectable combination anthelmintic (nitroxynil + clorsulon + ivermectin) against early immature Fasciola hepatica compared to triclabendazole combination flukicides given orally or topically to cattle. Vet Parasitol 162:278-84.

Martínez-Valladares M, Famularo M, Fernández-Pato $\mathrm{N}$, Castañón-Ordóñez L, Cordero-Pérez C, Rojo-Vázquez FA, 2010. Efficacy of nitroxynil against Fasciola hepatica resistant to triclabendazole in a naturally infected sheep flock. Parasitol Res 107:1205-11.

McKellar QA, Kinabo LDB, 1991. The pharmacology of flukicidal drugs. Brit Vet $\mathrm{J}$ 147:306.

McKinstry B, Halferty L, Brennan GP, Fairweather I, 2009. Morphological response of triclabendazole-susceptible and triclabendazole-resistant isolates of Fasciola hepatica to treatment in vitro with nitroxynil (Trodax). Parasitol Res 104:645-55.

Moreno L, Ceballos L, Lifschitz A, Bistoletti M, Alvarez L, Lanusse C, 2010. Combined subcutaneous administration of ivermectin and nitroxynil in sheep: age/body weight related changes to the kinetic disposition of both compounds. Res Vet Sci 88:315-20.

Whelan M, Kinsella B, Furey A, Moloney M, Cantwell H, Lehotay SJ, Danaher M, 2010. Determination of anthelmintic drug residues in milk using UPLC-MS/MS with rapid polarity switching. J Chromatogr A 1217:4612-22.

Whelan M, Bloemhoff Y, Furey A, Sayers R, Danaher M, 2011. Investigation of the persistence of nitroxynil residues in milk from lactating dairy cows by ultra performance liquid chromatography tandem mass spectrometry. J Agric Food Chem 59:7793-7. 